\title{
Letter to the editor: Casein micelles or casein supramolecules?
}

\section{S. Horne ${ }^{1,2}$}

McMahon and Oommen (2008) drew our attention to the IUPAC definition of the supramolecule as "a system consisting of 2 or more molecular entities held together and organized by means of intermolecular (non-covalent) binding interactions." This is now a direct quote from IUPAC Compendium of Chemical Terminology (IUPAC, 1997). McMahon and Oommen (2008) suggested that casein micelles could be described as supramolecules and subsequently McMahon et al. (2009) have adopted the term "casein supramolecule," employing it in this paper wherever "casein micelle" would have been normally encountered.

Is this unilateral change in terminology to be imposed without discussion and debate? I am of the opinion that this term, casein supramolecule, is too general and, indeed, could be an inaccurate descriptor of the casein micelle. Supramolecule is too general a term because the definition covers any aggregated casein or caseinate system from the detergent-like micelles of $\beta$-casein and the chain polymers of $\alpha_{S 1}$-casein (but excluding the polymers of $\kappa$-casein with their covalent disulfide links), through the sub-micellar entities of various models (if these exist) to any other aggregated entity found in caseinate solutions. The term could also be applied to many of the structures described by McMahon et al. (2009) in their proposed multi-stage mechanism of acid-induced gelation, be they the aggregates of released casein molecules, the pre-gel aggregates, or even the gel itself. How then do we distinguish casein micelles?

Native casein micelles contain calcium phosphate, a distinguishing characteristic. In most of the proposed models of the casein micelle, whether the dual-binding model of Horne (1998) and its structurally derived image from McMahon and Oommen (2008), the nano-

\footnotetext{
Received March 12, 2010.

Accepted April 12, 2010.

${ }^{1}$ Corresponding author: brendavi@aol.com

${ }^{2}$ Formerly of the Hannah Research Institute, Ayr, Scotland, KA6
} $5 \mathrm{HL}$. cluster model of Holt (1992), or the Schmidt modified sub-micelle model, this calcium phosphate is directly linked to the caseins. Whatever linkage might be proposed, even beyond these models, it is unlikely to be noncovalent in the sense implied in the IUPAC definition. "Casein supramolecule" is therefore an inaccurate descriptor of the casein micelle.

Nature engineered the casein micelle for a specific role in the packaging and transport of nutrients from mother to offspring in her milk. Our scientific forefathers may have erroneously described this entity as a micelle - the micelle was rather hazily defined at that time (Fox and Brodkorb, 2008) - but they recognized its peculiar and particular nature. Research since then has honed our understanding of the micelle's structure, stability, and interactions and has increased our knowledge of its response to processing conditions imposed in the manufacture of dairy products. Let us continue to refer to that entity as the casein micelle in recognition of its role, its properties, and its individuality. The meaning of the term "casein micelle" is clearly understood in dairy chemistry and other cognate areas. To my knowledge, no other scientific journal has adopted this arbitrary change in terminology for such a critically important component of milk. Let us reverse the policy in Journal of Dairy Science.

\section{REFERENCES}

Fox, P. F., and A. Brodkorb. 2008. The casein micelle: Historical aspects, current concepts and significance. Int. Dairy J. 18:677684.

Holt, C. 1992. Structure and properties of bovine casein micelles. Adv. Protein Chem. 43:63-151.

Horne, D. S. 1998. Casein interactions: Casting light on Black boxes, the structure of casein micelles. Int. Dairy J. 8:171-177.

IUPAC (International Union of Pure and Applied Chemistry). 1997. Compendium of Chemical Terminology. Vol. 1994, 66, 1169. 2nd ed. http://www.iupac.org/goldbook/S06153

McMahon, D. J., H. Du, W. R. McManus, and K. M. Larsen. 2009. Microstructural changes in casein supramolecules during acidification of skim milk. J. Dairy Sci. 92:5854-5867.

McMahon, D. J., and B. S. Oommen. 2008. Supramolecular structure of the casein micelle. J. Dairy Sci. 91:1709-1721. 